\title{
A novel, simple, and sensitive colorimetric method to determine aromatic amino acid aminotransferase activity using the Salkowski reagent
}

\author{
Michał Szkop • Piotr Sikora • Sławomir Orzechowski
}

Received: 10 August 2011 / Accepted: 16 November 2011 /Published online: 1 December 2011

(C) The Author(s) 2011. This article is published with open access at Springerlink.com

\begin{abstract}
This study describes the development of a new colorimetric assay to determine aromatic amino acid aminotransferase (ArAT) activity. The assay is based on the transamination of L-tryptophan in the presence of 2-oxoglutarate, which yields indole-3-pyruvate (IPyA). The amount of IPyA formed was quantified by reaction with the Salkowski reagent. Optimized assay conditions are presented for ArAT isozymes isolated from Pseudomonas putida. For comparative purposes, ArAT activity was also determined by highperformance liquid chromatography. ArAT activity staining in polyacrylamide gels with the Salkowski reagent is also presented.
\end{abstract}

\section{Introduction}

Aromatic amino acid aminotransferase (EC 2.6.1.57, ArAT) catalyzes the reversible transamination reaction that occurs between aromatic amino acids and 2-oxoglutarate. This enzyme is present in bacteria, usually in the form of several isozymes with different metabolic functions (Pedraza et al. 2004). In recent years, interest in ArAT has grown in connection with its involvement in the indole-3-acetic acid (IAA) biosynthetic pathway that occurs in many bacterial species. IAA is considered one of the most important factors in bacterially stimulated plant growth (Spaepen et al. 2007).

Among the available methods to determine ArAT activity, UV-spectrophotometric methods are used most frequently. Of these, the most common method is the enol-borate assay

\footnotetext{
M. Szkop $(\bowtie) \cdot$ P. Sikora $\cdot$ S. Orzechowski

Department of Biochemistry, Faculty of Agriculture and Biology,

Warsaw University of Life Sciences, SGGW,

Nowoursynowska 159,

02-776 Warsaw, Poland

e-mail: michal_szkop@sggw.pl
}

(Andreotti et al. 1994; Simpson et al. 1997; Ward et al. 2002; Pirkov et al. 2008; Lu and Austic 2009) developed by Lin et al. (1958). This assay is based on the absorbance measurement of aromatic 2-oxo acids enol tautomer-borate complex. Due to the slow tautomerization of aromatic 2-oxo acids from the keto form to the enol form, it is necessary to add tautomerase or arsenate to accelerate this reaction. The advantage of this method is its high sensitivity; however, its disadvantage lies in its complexity and the number of steps required. Additionally, this method, similar to other UVspectrophotometric methods, requires the use of optically clear solutions, which significantly hampers its ability to accurately assay ArAT activity in crude bacterial extracts. Another problem is the high absorbance values obtained for blanks (Diamondstone 1966).

Therefore, the aim of this study was to develop a sensitive, but also simple, ArAT activity assay that could be successfully applied to test crude bacterial extracts. For this purpose, we utilized the Salkowski reagent. This reagent was originally developed for indole determination (Salkowski 1885) and consists of $\mathrm{FeCl}_{3}$ dissolved in a concentrated oxidizing acid; currently, it is applied almost exclusively for the detection and quantitative determination of IAA concentrations in bacterial culture supernatants. In order to increase its sensitivity and specificity for IAA, multiple formulations of the Salkowski reagent have been developed; these differ in $\mathrm{FeCl}_{3}$ concentrations or in the type of acid used (Gordon and Weber 1951; Pilet and Chollet 1970). However, Glickmann and Dessaux (1995) showed that in addition to IAA, indolepyruvate (IPyA) and indoleacetamide react with the Salkowski reagent resulting in the formation of colored complexes. Therefore, the method presented here for ArAT activity determination is based on the reaction of the Salkowski reagent with IPyA, the oxoproduct of L-tryptophan transamination. To the best of our 
knowledge, this is the first report demonstrating the applicability of this reagent for the determination of ArAT activity.

\section{Methods and results}

Of the various Salkowski reagents formulations tested in this study, the formulation that consisted of $10 \mathrm{mmol} / \mathrm{L}$ $\mathrm{FeCl}_{3}$ dissolved in $35 \% v / v \mathrm{H}_{2} \mathrm{SO}_{4}$ was the most sensitive to IPyA. The colored complex formed by the reaction of IPyA with this reagent showed maximum absorbance at $\lambda=$ $530 \mathrm{~nm}$ (pink). To determine the sensitivity and the operating range of the method, a calibration curve for IPyA (Sigma-Aldrich, Inc., St. Louis, MO, USA) was created (Fig. 1). Eight different concentrations of this compound, ranging in concentration from 3.8 to $92 \mu \mathrm{mol} / \mathrm{L}$, were prepared in $0.1 \mathrm{~mol} / \mathrm{L}$ phosphate buffer containing $10 \mathrm{mmol} / \mathrm{L}$ L-tryptophan (Roth, Karlsruhe, Germany). Next, $1 \mathrm{~mL}$ of the Salkowski reagent was added to $0.5 \mathrm{~mL}$ of each standard solution; solutions were mixed and incubated for $10 \mathrm{~min}$ in the dark at room temperature. Absorbance was then measured at $\lambda=530 \mathrm{~nm}$ for each sample (Spectroquant Pharo 300, Merck); the colored complex was stable for at least $30 \mathrm{~min}$. The spectrophotometer was calibrated against a blank solution (without IPyA) mixed with the Salkowski reagent. In the tested range of IPyA concentrations, the measured absorbance values increased proportionally with the IPyA concentration (coefficient of determination, $R^{2}=$ 0.9967). Additionally, the molar absorption coefficient was determined at 7,500 L/mol cm, which indicates high assay sensitivity; in comparison, for NADH, the molar absorption coefficient is $6,220 \mathrm{~L} / \mathrm{mol} \mathrm{cm}$. Next, the developed method was used to determine the activity of ArAT isozymes isolated from a strain Pseudomonas putida. The strain was obtained from the collection of the Department of Biochemistry, SGGW, and was identified using the ribotyping

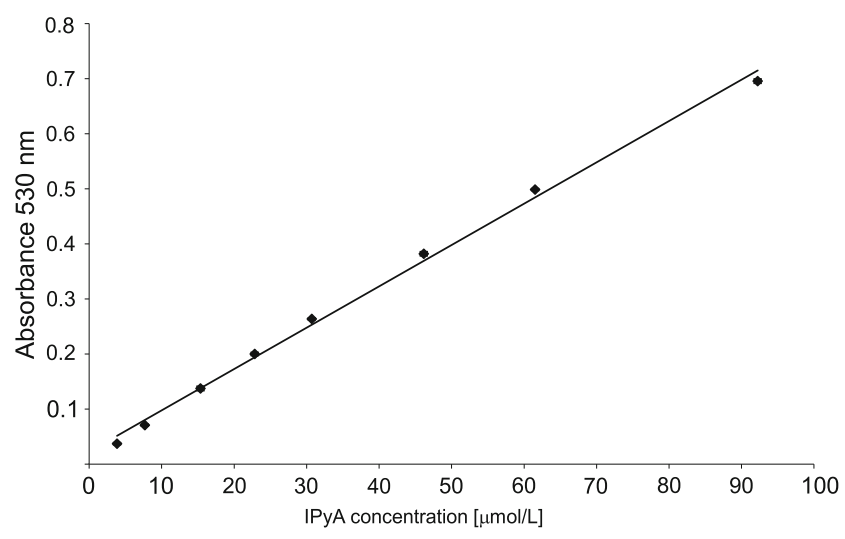

Fig. 1 Calibration curve for IPyA. Each data point represents the mean \pm SD of four determinations. The coefficient of determination was calculated to be 0.9967 . Regression line $y=0.0075, x=0.0225$ method by Blirt S.A. DNA-Gdańsk, Poland. The bacteria were cultivated in King B liquid medium (King et al. 1954) for $48 \mathrm{~h}$. Bacterial cultures were then centrifuged and the bacterial pellets were washed twice and resuspended in $0.2 \mathrm{~mol} / \mathrm{L}$ phosphate buffer $(\mathrm{pH} 8.0)$ before being broken with ultrasonication. Crude bacterial extracts were used as the enzyme source for the assays. The transamination reactions were carried out in a total volume of $0.5 \mathrm{~mL}$. The preincubation mixture consisted of $0.1 \mathrm{~mol} / \mathrm{L}$ phosphate buffer, $\mathrm{pH} 8.0 ; 10 \mathrm{mmol} / \mathrm{L}$ L-tryptophan; $10 \mu \mathrm{mol} / \mathrm{L}$ pyridoxal phosphate and the enzyme preparation. After a 3-min preincubation at $35^{\circ} \mathrm{C}$, the reactions were initiated with the addition of 2-oxoglutarate at a final concentration of $3 \mathrm{mmol} / \mathrm{L}$; all reactions were performed at $35^{\circ} \mathrm{C}$. A blank reaction mixture containing no enzyme was included and used to calibrate the spectrophotometer. The reactions were terminated through the addition of $1 \mathrm{~mL}$ of the Salkowski reagent. After $10 \mathrm{~min}$ of incubation in the dark at room temperature, the absorbance at $\lambda=530 \mathrm{~nm}$ was measured. As shown in Fig. 2, a linear relationship was obtained between the absorbance, enzyme concentration, and the reaction time. It is important to note that in this method, the transamination reaction is terminated and the formation of the colored complex is initiated in a single step. The deproteinization step is also unnecessary due to the solubility of proteins in the Salkowski reagent. After the addition of this reagent to the reaction mixture, the solution remains optically clear and without any pellet.

For comparative purposes and to verify the specificity of the method, we determined IPyA and L-glutamate concentrations in parallel, which are formed in equimolar amounts during transamination reactions (Fig. 3). The transamination reactions were carried out in a total volume of $1 \mathrm{~mL}$ using

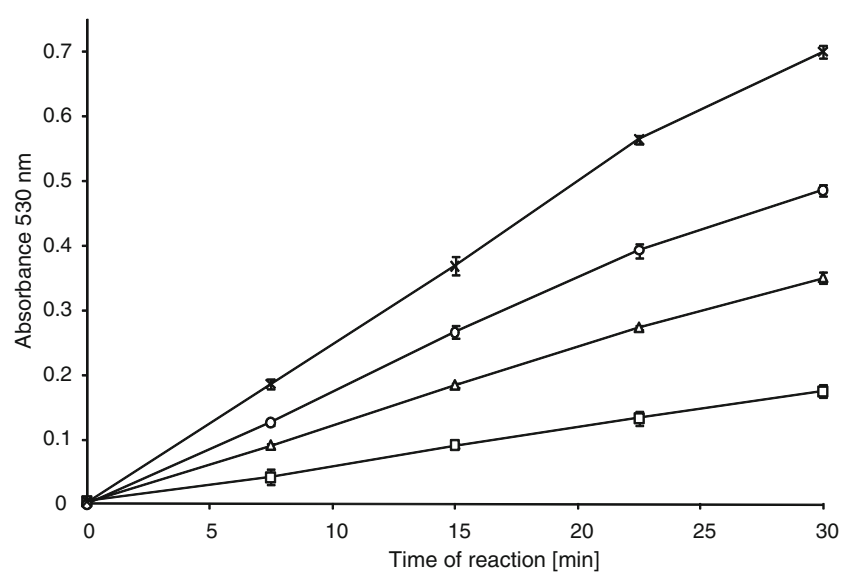

Fig. 2 Correlation between absorbance and the reaction time with four different enzyme concentrations. Transamination reactions were performed in a standard reaction mixture containing $10 \mu \mathrm{L}$ (white square), $20 \mu \mathrm{L}$ (white triangle), $30 \mu \mathrm{L}$ (white circle), or $40 \mu \mathrm{L}$ (ex symbol) of the crude enzyme preparation. Each data point represents the mean \pm $\mathrm{SD}$ of three determinations 


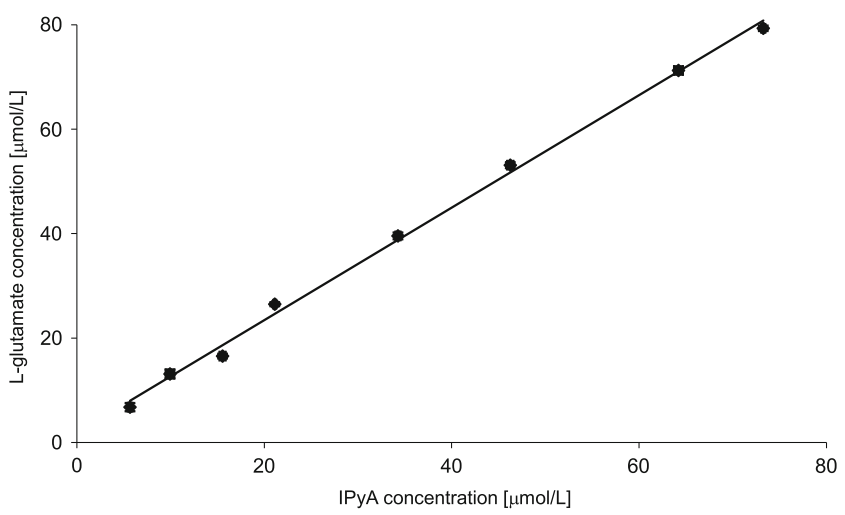

Fig. 3 Confirmation assay specificity. The IPyA concentrations determined with the Salkowski reagent are plotted against L-glutamate concentrations measured with RP-HPLC. Both compounds were analyzed as transamination products. The coefficient of determination was calculated to be 0.9973 . Each data point represents the mean of four \pm SD determinations. Regression line $y=1.078, x+1.8472$

the standard incubation mixture. After eight different incubation times of the reaction, $0.5 \mathrm{~mL}$ of the incubation mixture was mixed with $1 \mathrm{~mL}$ of the Salkowski reagent; the IPyA concentration was then calculated from the obtained absorbance based on a calibration curve. To determine the L-glutamate concentration, the second $0.5 \mathrm{~mL}$ of the reaction mixture was mixed with $125 \mu \mathrm{L}$ of $2 \mathrm{~mol} / \mathrm{L}$ borate buffer, $\mathrm{pH} 12.5$, containing $0.7 \mathrm{~mol} / \mathrm{L}$ mercaptoethanol. These samples were then centrifuged and filtered (Amicon Ultra $0.5 \mathrm{~mL}$ centrifugal filters Z677094, SigmaAldrich); the filtrate was derivatized with orthophthalic aldehyde (Van Eijk et al. 1993) and subsequently analyzed using high-performance liquid chromatography (binary HPLC 1525 pump, Waters). Separations were performed on $\mathrm{C} 18$ columns (Symmetry $4.6 \times 150 \mathrm{~mm}, 5 \mu \mathrm{m}$, Waters) and fluorimetric detection $\left(\lambda_{\mathrm{ex}}=338 / \lambda_{\mathrm{em}}=425 \mathrm{~nm}\right.$, Model 474 , Waters) was used. The samples were automatically derivatized through the autosampler (Model 717plus, Waters) in the following manner. First, $100 \mu \mathrm{L}$ of orthophthalic aldehyde solution $(15 \mathrm{mg} / \mathrm{mL}$ in $v / v 50 \%$ methanol) was added into $450 \mu \mathrm{L}$ of the filtered reaction mixture. After two cycles of mixing and $3 \mathrm{~min}$ of delay, $100 \mu \mathrm{L}$ of sample was injected into the column. Chromatographic separation was carried out using $60 \mathrm{mmol} / \mathrm{L}$ phosphate buffer, $\mathrm{pH} 6.8$, (eluent A) and $80 \%$ acetonitrile (eluent B). The orthophthalic derivative of L-glutamate was eluted using a 12-min $0-100 \%$ eluent B linear gradient. The areas under the corresponding peaks were recalculated to determine the concentration of L-glutamate produced in the course of the transamination reaction based on the prepared calibration curve. The resulting coefficient of determination between the concentrations of the two transamination products (L-glutamate and IPyA) determined independently was $R^{2}=0.9973$. This result suggests that in the applied reaction mixture, IPyA was the only indole product formed from L-tryptophan that reacted with the Salkowski reagent and that the method specifically assessed ArAT activity. To further confirm the specificity of the method, electrophoretic separation of proteins from the crude bacterial extracts was performed under native conditions ( $50 \mu \mathrm{g}$ of protein per lane), and one of the gels was stained for ArAT activity (L-tryptophan and 2oxoglutarate were used as substrates) using a common method based on tetrazolium salt reduction described by Pedraza et al. (2004; Fig. 4c). In the control gel stained with this method, 2-oxoglutarate was omitted from the incubation mixture (Fig. 4d). Thus, the presence of any bands in this gel would not be the result of ArAT activity. The second gel was stained with the Salkowski reagent. For this purpose, the gel was covered with tissue paper soaked in a mixture of $0.1 \mathrm{~mol} / \mathrm{L}$ phosphate buffer, $\mathrm{pH} 8.0 ; 10 \mathrm{mmol} / \mathrm{L}$ L-tryptophan; $3 \mathrm{mmol} / \mathrm{L}$ 2-oxoglutarate; and $10 \mu \mathrm{mol} / \mathrm{L}$ pyridoxal phosphate (Fig. 4b). Here also, 2-oxoglutarate was omitted from the incubation mixture for the control gel (Fig. 4a). After $20 \mathrm{~min}$ of incubation, the Salkowski reagent was poured over the gels in order to stain formed IPyA. The same two bands of ArAT activity, which were absent in the controls, were observed in gels stained with both methods. These results demonstrate the existence of two ArAT isozymes with different electrophoretic mobility in the studied P. putida strain and confirm the specificity of the presented method.

\section{Summary}

In this paper, we present a new ArAT activity assay based on the reaction of IPyA with the Salkowski reagent. This method is characterized by its high sensitivity, specificity, and simplicity of use. It can be applied for precise measurements of ArAT activity in crude bacterial extracts and can also be very useful for routine activity assays during ArAT purification. Moreover, this method can also be used to stain gels for ArAT activity.

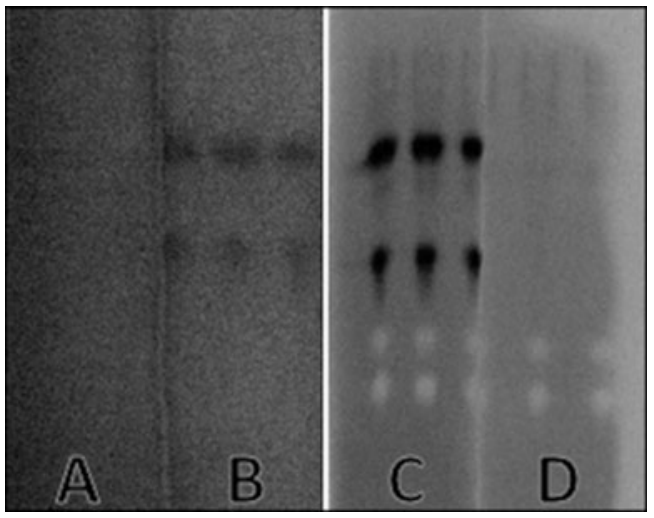

Fig. 4 ArAT activity zymograms. $a, b$ Gels stained with the Salkowski reagent; $c, d$ gels stained with the formazan-tetrazolium system; $a$ and $d$ controls 
Acknowledgments This work was supported by the Polish Ministry of Science and Higher Education (grant no. N N310 304639).

Open Access This article is distributed under the terms of the Creative Commons Attribution Noncommercial License which permits any noncommercial use, distribution, and reproduction in any medium, provided the original author(s) and source are credited.

\section{References}

Andreotti G, Cubellis MV, Nitti G, Sannia G, Mai X, Marino G, Adams MWW (1994) Characterization of aromatic aminotransferases from the hyperthermophilic archaeon Thermococcus litoralis. Eur J Biochem 220:543-549

Diamondstone TI (1966) Assay of tyrosine transaminase activity by conversion of $p$-hydroxyphenylpyruvate to $p$-hydroxybenzaldehyde. Anal Biochem 16:395-401

Glickmann E, Dessaux Y (1995) A critical examination of the specificity of the Salkowski reagent for indolic compounds produced by phytopathogenic bacteria. Appl Environ Microbiol 61:793-796

Gordon SA, Weber RP (1951) Colorimetric estimation of indoleacetic acid. Plant Physiol 26:192-195

King EO, Ward MK, Raney DE (1954) Two simple media for the demonstration of pyocyanin and fuorescein. J Lab Clin Med 44:301-302

Lin ECC, Pitt BM, Civen M, Knox WE (1958) The assay of aromatic amino acid transaminations and keto acid oxidation by the enolborate tautomerase method. J Biol Chem 233:668-673
Lu J, Austic RE (2009) Phenylalanine-pyruvate aminotransferase activity in chicks subjected to phenylalanine imbalance or phenylalanine toxicity. Poult Sci 88:2375-2381

Pedraza RO, Ramirez-Mata A, Xiqui ML, Baca BE (2004) Aromatic amino acid aminotransferase activity and indole-3-acetic acid production by associative nitrogen-fixing bacteria. FEMS Microbiol Lett 233:15-21

Pilet PE, Chollet R (1970) Sur le dosage colorimetrique de l'acide indolylacetique. C R Acad Sci Ser D 271:1675-1678

Pirkov I, Norbeck J, Gustafsson L, Albers E (2008) A complete inventory of all enzymes in the methionine salvage pathway. FEBS J 275:4111-4120

Salkowski E (1885) Uber das verhalten der skatolcarbonsaure im organismus. Z Physiol Chem 9:23-33

Simpson RM, Nonhebel HM, Christie DL (1997) Partial purification and characterisation of an aromatic amino acid aminotransferase from mung bean (Vigna radiata L. Wilczek). Planta 201:71-77

Spaepen S, Vanderleyden J, Remans R (2007) Indole-3-acetic acid in microbal and microorganism-plant signaling. FEMS Microbiol Rev 31:425-448

Van Eijk HMH, Rooyakkers DR, Deutz NEP (1993) Rapid routine determination of amino acids in plasma by high-performance liquid chromatography with a 2-3 $\mu \mathrm{m}$ Spherisorb ODS II column. J Chromatogr 620:143-148

Ward DE, De Vos WM, Van der Oost J (2002) Molecular analysis of the role of two aromatic aminotransferases and a broad-specificity aspartate aminotransferase in the aromatic amino acid metabolism of Pyrococcus furiosus. Archaea 1:133-141 